\title{
Prevalence of Hydatid Cysts in Slaughtered Animals from Different Areas of Libya
}

\begin{abstract}
The present study reports on the infection rates of hydatid cysts in both sexes and different age groups of sheep, camels and cattle from govemment abattoirs in different parts of Libya. An infection rate of $10.06 \%$ was recovered among 32971 all ruminants, (sheep, camels and cattle). Out 25314 of sheep, 2659 (10.52\%) were infected. O ut 7496 of camels, 940 (12.54\%) were infected. Out 161 of cattle, 17 (10.56\%) were infected. As regards to the infected organs, liver was seen to be the most commonly infected organ in sheep and cattle $(46.03 \%$, $52.94 \%)$ respectively, but in camels, it was the lung (55.21\%). The fertility rates of hydatid cysts were $80 \%$ in sheep, $84 \%$ in camels and $0 \%$ in cattle cysts. In sheep, the fertility rate of liver hydatid cysts was higher than in otherorgans $(53.85 \%)$, but in camels, the fertility rate in the lung was higher than that of other infected organs (66.7\%).
\end{abstract}

\section{Introduction}

Unilocular hydatid cyst, also known as hydatidosis, is a zoonotic disease caused by the cystic larval stage of the tapeworm Echinococcus granulosus. Hydatid cysts in livestock are diagnosed when animals are sent to abattoirs for slaughter. This disease has a worldwide distribution and used to be particularly common in developing and undeveloped countries, including the Mediterranean region. However, the greatest prevalence of hydatid disease in livestock is found in countries of the temperate zones, including central Asia, China, Australia and parts of Africa [1]. For example, the prevalence of cystic echinococcosis is higher in livestock animals in North Africa, especially Libya [2,3]. Studies conducted in the past four decades have revealed a high prevalence of hydatid disease in livestock animals in Libya. In addition, Dakkak [4] observed the prevalence in Libya ranges from endemic to hyperendemic, and camels act as the most important intermediate hosts in the life cycle of the parasite. The problem in Libya is further compounded by the fact that in several regions in the country, the disease is endemic, and home slaughter is practiced, and few abattoirs have sufficient veterinary supervision. Apart from camels, dogs are usually the main source of infection for livestock animals when they graze on contaminated pastures and get infected with the eggs of the parasite.

For instance, past records in the government abattoirs indicated high rates of infection in slaughtered animals, especially in sheep and camels. Such a situation has a negative economic impact as the disease causes not only losses in yield in terms of internal organs and other products like milk and meat, but also productivity in general [5].

The high incidence of hydatidosis in the intermediate host animals has been noted by a number of researchers in Libya [6-11].

The objective of the present survey is to estimate the prevalence rate of hydatidosis infecting different organs of livestock slaughtered in Libya. In addition, the present survey will also investigate the relationship between the infected rates of slaughtered animals and
Journal of Veterinary Science \& Medicine

\section{Layla O Elmajdoub ${ }^{1 *}$ and Wahab A Rahman ${ }^{2}$}

${ }^{1}$ Department of Zoology, Misurata University, Libya

${ }^{2}$ School of Food Science and Technology, Universiti Malaysia Terengganu, Terengganu

\section{Address for Correspondence}

Layla Elmajdoub, Department of Zoology, Misurata University, Libya, Tel: 0913101356; E-Mail: elmajdoublayla@yahoo.com

Copyright: ( 2014 Elmajdoub LO, et al. This is an open access article distributed under the Creative Commons Attribution License, which permits unrestricted use, distribution, and reproduction in any medium, provided the original work is properly cited.

Submission: 29 September 2014

Accepted: 20 October 2014

Published: 24 October 2014

Reviewed \& Approved by: Dr. Mark Brown, Professor and faculty in the Department of Clinical Sciences at Colorado State University, USA

seasonal variations. The fertility and sterility rates and localization of hydatid cysts are examined.

\section{Material and Methods}

\section{Description of the study area}

The present study was conducted from January to the end of December 2010 in Libya. It is the fourth largest country in Africa with an approximate area of $1.754 .000 \mathrm{~km}^{2}$ and an approximate population of 6.6 million according to a 2006 census. Most of the population is found in the main coastal cities of Tripoli, Misurata, and Benghazi. The study was carried out in the main government abattoirs in different areas in Libya.

\section{Examination of slaughtered livestock}

The animals examined in the study were sheep, camels and cattle. All sheep (Ovis aries) examined were of the Libyan Barbary breed while the camels (Camelus dromedaries) were of Libyan breed. However, the cattle (Bos taurus) examined were of two breeds, namely, Jersey and local. A total of 32,971 different slaughtered animals in all the study areas were examined for hydatid cysts at the time of slaughter.

\section{Selection of unilocular hydatid cysts for examination}

The hydatid cysts were identified as according to the descriptions of the veterinarians in the slaughtered animals and were examined for degeneration and calcification. Generally, most of the cysts were recovered from the livers and lungs, with a few from spleen and mesentery illustrated in Table 1.

\section{Assessment of the fertility of hydatid cysts}

The hydatid fluid from each cyst was aspirated by means of a

Table 1: Number of hydatid cysts from different organs in slaughtered animals.

\begin{tabular}{|c|c|c|c|c|}
\hline & Liver & Lung & Spleen & Mesentery \\
\hline Sheep & 135 & 105 & 4 & 16 \\
\hline Camel & 28 & 64 & 8 & 0 \\
\hline Cattle & 6 & 6 & 0 & 0 \\
\hline & & & & 372 \\
\hline
\end{tabular}


sterile syringe and a large-sized needle and then transferred to a sterile container. The collected fluid was left to sediment after which a drop of each sample of cyst sand was placed on a slide together with a drop of lacto phenol and then covered with a cover slip in the presence of protoscoleces or brood capsules or fragments of the germinal layer under the microscope. If protoscolex was not present in the hydatid fluid, it was then centrifuged at 5000 RPM for $5 \mathrm{~min}$. If still negative, the germinal layer was examined by immersing in glycerin between two microscope slides for the presentation of protoscoleces or brood capsules.

\section{Examination of viability of protoscoleces}

The viability of protoscoleces was determined by staining with $0.1 \%$ aqueous eosin solution, and observing the motility of flame cells. Usually viable protoscoleces do not take up the stain immediately until 10 min later, but dead (enviable) protoscoleces will take up the stain immediately [12]. In this study, 5 fertile cysts were randomly selected from each of liver and lungs of slaughtered sheep and camel. In order to determine the viability of protoscoleces, each fertile cyst was examined in five replicates. Then 30 protoscoleces were randomly selected to estimate the number of viable protoscoleces.

\section{Data analysis}

Prevalence was calculated according to the proportion of the infection rates of slaughtered animals. Analysis of variance was assessed to compare several groups using ANOVA, correlation coefficients ( $r$ ) between infection rates, according to the season and intensity of infection and age, and sex. In all tests, a P- value of $<0.05$ was considered indicative of a statistically significant difference. All statistical tests were performed using SPSS 19 software.

\section{Results}

\section{Variations of hydatid cyst infection rates in all examined} livestock

Table 2 shows the infection rates of all slaughtered animals in the study areas at different seasons of the year 2010 .
From a total of 32,971 animals examined, the total prevalence rate was $10.97 \%$. From a total of 6333 slaughtered animals examined in winter, $13.12 \%$ were infected, and for spring, out of 7754 slaughtered animals examined, $12.4 \%$ were infected. For summer and autumn, the values were $10.13 \%$ and $9.07 \%$, respectively; also, there was no significant difference between seasons for all infected animals.

The overall infection rate in slaughtered sheep was $10.52 \%$. As shown in Table 3, the sheep were infected and high in winter and spring at $12.6 \%$ and $11.9 \%$ respectively, but low in summer and autumn. There were no statistical difference between slaughtered sheep, but analysis of all slaughtered animals (sheep, camels, and cattle) in terms of the homogeneity test revealed a high significance $(P<0.01)$.

In this study, 7496 camels were examined, and $12.5 \%$ were infected. Also, 161 cattle were examined and (10.6\%) were infected with hydatid cysts (Table 3). It was also found that the infection rate for slaughtered camels during winter was high (16.2\%), followed by spring and summer, $(13.8 \% ; 13.1 \%)$ respectively, whereas in autumn, the lowest infection rate was lowest $(8.8 \%)$. Also, it was found that while there were significant differences between infection rates for winter, spring, and summer $(P<0.05)$, there was no significant difference between infection rates for autumn and the other seasons. In the case of slaughtered cattle, it was observed that there was a high infection rate in autumn (25\%), followed by spring (13.0\%), summer (10.2\%), and winter (6.3\%), but with no significant differences.

\section{Distribution of hydatid cysts, according to sex}

The overall rate of infection for male slaughtered livestock was $50.8 \%$, while for females it was $49.2 \%$; but not significantly different between the sexes, the infection rates of hydatid cysts in slaughtered sheep based on sex which was $50.8 \%$ and $49.2 \%$ respectively. It was also found that there was no significant difference between their infection rates. Also, it was observed that slaughtered female livestock had the highest rate of infection in cattle and camels $(76.7 \%$; $50.6 \%$ respectively), (Table 4). However, it was observed that there was

Table 2: Seasonal variation of infection rate in the livestock from overall regions.

\begin{tabular}{|c|c|c|c|c|c|c|c|c|c|c|c|c|}
\hline & \multicolumn{3}{|c|}{ Winter } & \multicolumn{3}{|c|}{ Spring } & \multicolumn{3}{|c|}{ Summer } & \multicolumn{2}{|c|}{ Autumn } & \multirow[t]{2}{*}{ Total } \\
\hline & Dec & Jan & Feb & Mac & Apr & May & Jun & Jul & Aug & Sep & Nov & \\
\hline Slaughtered animals & \multicolumn{3}{|c|}{6333} & \multicolumn{3}{|c|}{7754} & \multicolumn{3}{|c|}{10667} & \multicolumn{2}{|c|}{8217} & 32971 \\
\hline Infected animals & \multicolumn{3}{|c|}{$831(13.1 \%)$} & \multicolumn{3}{|c|}{959 (12.4\%) } & \multicolumn{3}{|c|}{$1081(10.1 \%)$} & \multicolumn{2}{|c|}{$745(9.07 \%)$} & $3616(10.96 \%)$ \\
\hline Mean \pm S.E & \multicolumn{3}{|c|}{$47.7 \pm 8.97$} & \multicolumn{3}{|c|}{$53.3 \pm 8.17$} & \multicolumn{3}{|c|}{$59 \pm 10.94$} & \multicolumn{2}{|c|}{$41.4 \pm 6.85$} & $50.4 \pm 4.4$ \\
\hline Statistical analysis & \multicolumn{6}{|l|}{1} & & & & & & NS \\
\hline
\end{tabular}

$N S=$ nonsignificant different $P>0.05$

Table 3: Seasonal variation of infection rate according of infected animals.

\begin{tabular}{|c|c|c|c|c|c|c|c|c|c|c|c|c|}
\hline & \multicolumn{3}{|c|}{ Winter } & \multicolumn{3}{|c|}{ Spring } & \multicolumn{3}{|c|}{ Summer } & \multicolumn{3}{|c|}{ Autumn } \\
\hline & Sheep & Camel & Cattle & Sheep & Camel & Cattle & Sheep & Camel & Cattle & Sheep & Camel & Cattle \\
\hline $\begin{array}{l}\text { Slaughtered } \\
\text { animals }\end{array}$ & 5279 & 1006 & 48 & 5718 & 1990 & 46 & 8125 & 2483 & 59 & 6192 & 2017 & 8 \\
\hline $\begin{array}{l}\text { Infected } \\
\text { animals }\end{array}$ & $\begin{array}{c}665 \\
(12.6 \%) \\
\end{array}$ & $163(16.2 \%)$ & $3(6.25 \%)$ & $\begin{array}{c}679 \\
(11.9 \%) \\
\end{array}$ & $274(13.7 \%)$ & $6(13.04 \%)$ & $\begin{array}{c}750 \\
(9.23 \%) \\
\end{array}$ & $\begin{array}{c}325 \\
(13.09 \%) \\
\end{array}$ & $\begin{array}{c}6 \\
(10.2 \%)\end{array}$ & $\begin{array}{c}565 \\
(9.12 \%) \\
\end{array}$ & $\begin{array}{c}178 \\
(8.82 \%)\end{array}$ & $\begin{array}{c}2 \\
(25 \%)\end{array}$ \\
\hline Mean \pm S.E & $55.4 \pm 7.9$ & $54.3 \pm 4.06^{*}$ & $1 \pm 0.57$ & $69.1 \pm 6.5$ & $91.3 \pm 6.34^{*}$ & $2 \pm 1.53$ & $62.5 \pm 8.1$ & $108.3 \pm 7.5^{*}$ & $2 \pm .57$ & $47.1 \pm 8.2$ & $59.3 \pm 106$ & $0.67 \pm 0.6$ \\
\hline
\end{tabular}

* Slight significant difference $\mathrm{P}<0.05$ 
no significant difference between the infection rate for all male and female livestock.

\section{Infection rates of organs}

The liver and lungs were the most commonly infected $(43.1 \%$ and $42.9 \%$, respectively), followed by other organs such as the mesentery $(0.5 \%)$ and spleen $(0.4 \%)$. Based on the seasons, the infection rates for liver and lung were comparable ( $43.1 \%$ and $42.1 \%$, respectively) for all seasons, unlike for organs such as mesentery and spleen. A statistical analysis observed a non-significant difference (Table 5).

The most commonly infected organ in sheep and cattle was the liver $(46.03 \%$; $52.9 \%$ respectively). But in the case of camel, the lung was the most commonly infected (55.2\%). It was also observed that the double infection of liver and lung in cattle was higher than in sheep (14.5\%), and camels $(9.47 \%)$, whereas, organs such as mesentery and spleen had lower rates of infection compared to the liver and lung (Table 6). However, when statistical analysis was carried out among the infected organs, it was observed that there was a non-significant difference for all infected organs. Furthermore, the correlation relationship among the locations of infection was found to be a positive, but weak correlation $(r=0.132)$ for all infected livestock.

\section{Fertility of hydatid cysts}

The fertility rate of 372 examined hydatid cysts selected from overall slaughtered livestock was observed to be $78.5 \%$, while $15.1 \%$ of the cysts were sterile, and $6.5 \%$ cysts were calcified. Figure 1 and Figure 2 show fertile, sterile and calcified cysts.

Generally, the hydatid cysts of camels (84\%) were more fertile than those of sheep (80\%), whereas all cattle cysts were sterile and calcified $(58.3 \%$; $41.6 \%$ respectively (Table 7$)$. Also, it was observed that there was a non-significant difference in fertility rates of all slaughtered animals.

In terms of the fertility rate for hydatid cysts selected from different slaughtered animal species in all the study areas, it was observed that in pulmonary cysts, it was $47.3 \%$, which was higher than that for liver $(46.2 \%)$ and other organs, such as the mesentery $(3.76 \%)$ and spleen $(2.71 \%)$. However, most of the calcified cysts were found in hepatic cysts $(45.8 \%)$, followed by pulmonary cysts (41.6\%) and mesentery $(8.3 \%)$ and spleen $(4.17 \%)$.

Table 8 illustrates that the pulmonary cysts from slaughtered camels $(66.7 \%)$ were more fertile than that in other organs in the same animal as well as in slaughtered sheep as the hepatic cysts were the most commonly infected organs in slaughtered sheep (53.8\%). On the other hand, the hepatic cysts were more calcified than the pulmonary cysts in slaughtered sheep and cattle $(50 \%, 60 \%)$, whereas, in camels, the pulmonary cysts $(57.1 \%)$ were more calcified than that of hepatic cysts.

In contrast, all examined cysts from slaughtered cattle were sterile. The statistical difference appeared significant $(P<0.05)$ among fertile cysts from infected organs of slaughtered sheep. However, among infected organs of slaughtered camels there was a non-significant difference (Table 9)

\section{Viability rate of hydatid cysts}

The viability rate of protoscoleces that were recovered from all slaughtered livestock was $75.6 \%$ for the first 5 min using $1 \%$ eosin and $54.7 \%$ after $10 \mathrm{~min}$. In terms of the different groups of slaughtered animals, the viability rate of protoscoleces for the first $5 \mathrm{~min}$ was $76.1 \%$ in sheep which was higher than that for camels $(75.2 \%)$. However, after $10 \mathrm{~min}$, the protoscoleces in camels that were still viable was $60.9 \%$, which was higher than that in sheep (48.4\%), as illustrated in Figure 2. In terms of the viability rate of protoscoleces for organ, it was $79.7 \%$ of the lung of camels which was higher than that in sheep (75.6\%) for the first $5 \mathrm{~min}$, whereas, for sheep liver it was $(76.5 \%)$ which was higher than that in camels $(70.7 \%)$ for the first $5 \mathrm{~min}$. However, after $10 \mathrm{~min}$, it was found that the viability rate of protoscoleces for the liver and lung of camels was $60.93 \%$, and $6.93 \%$, respectively, which were higher than those of sheep $(50.7 \%, 46.13 \%$ respectively).

Table 4: The mean and infection ratio of hydatid cysts based on sex.

\begin{tabular}{|c|c|c|c|c|c|}
\hline & \multicolumn{4}{|c|}{ Male } & \multicolumn{2}{c|}{ Female } \\
\hline & Sheep & Camel & Cattle & Sheep & Camel \\
\hline Total infection & $1836(50.8 \%)$ & $464(49.3 \%)$ & $4(23.5 \%)$ & $1780(49.2 \%)$ & $476(50.6 \%)$ \\
\hline Mean \pm S.E & $25.5 \pm 2.5$ & $38.7 \pm 3.82$ & $0.33 \pm 0.19$ & $24.9 \pm 2.3$ & $39.7 \pm 4.46$ \\
\hline
\end{tabular}

Table 5: The infection rate of hydatid cysts in different organs.

\begin{tabular}{|c|c|c|c|c|c|}
\hline & Liver & Lung & Both liver \& lung & Mesentery & $17(0.5 \%)$ \\
\hline Total infection & $1557(43.1 \%)$ & $1551(42.1 \%)$ & $478(13.2 \%)$ & $13(0.4 \%)$ \\
\hline Mean \pm S.E & $21.5 \pm 2.07$ & $21.8 \pm 2.16$ & $6.63 \pm 0.59$ & $0.24 \pm 0.074$ \\
\hline
\end{tabular}

Table 6: The rate of infection of hydatid cysts based on organ infected.

\begin{tabular}{|c|c|c|}
\hline & Sheep & Camel \\
\hline Liver & $1224(46.03 \%)$ & $324(34.5 \%)$ \\
\hline Lung & $1027(38.6 \%)$ & $519(55.2 \%)$ \\
\hline Both liver \& lung & $386(14.5 \%)$ & $59(9.5 \%)$ \\
\hline Mesentery & $17(0.64 \%)$ & Non (17.7\%) \\
\hline Spleen & $5(0.19 \%)$ & $8(0.85 \%)$ \\
\hline
\end{tabular}




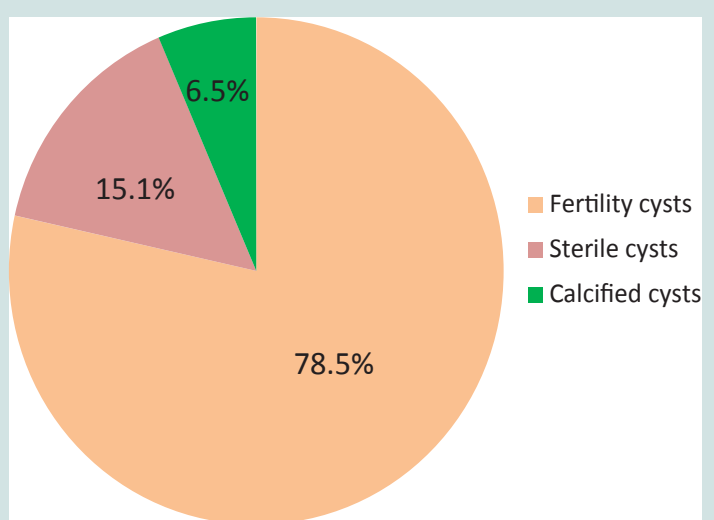

Figure 1: Overall fertility rate of examined hydatid cysts from slaughtered livestock.
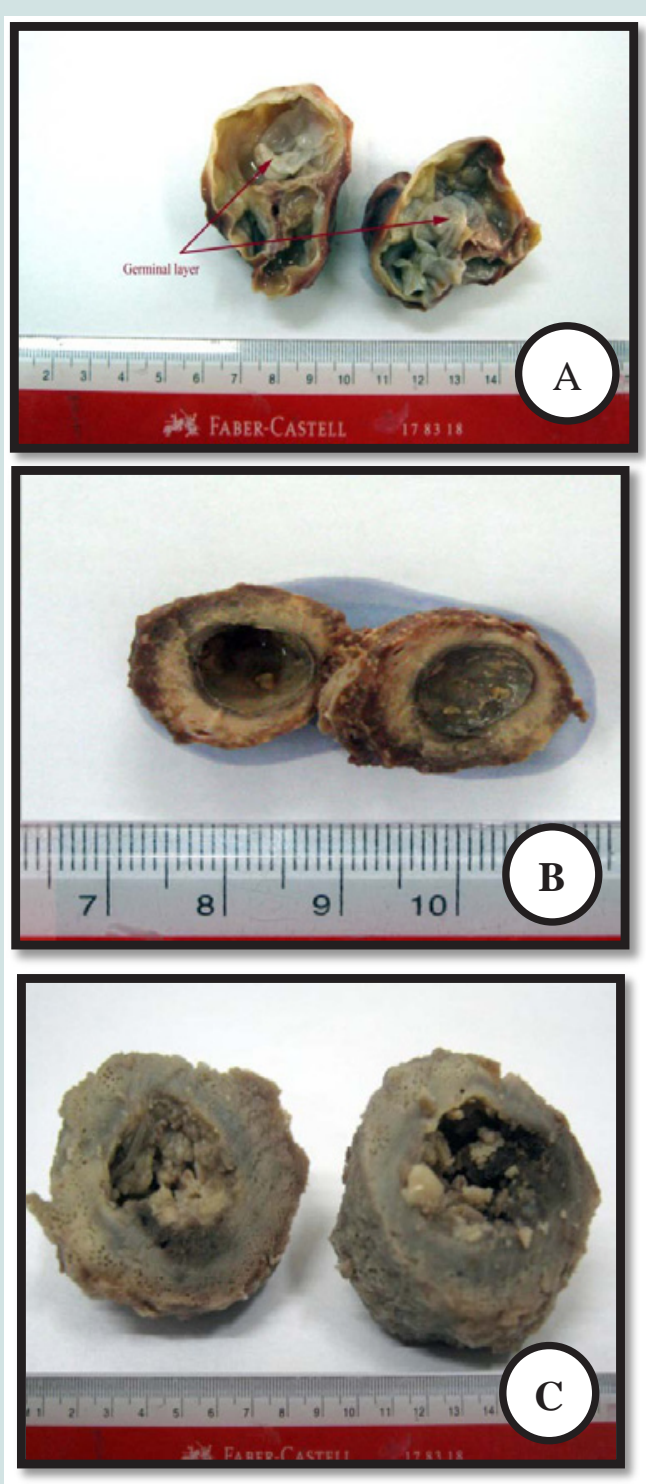

Figure 2: Unilocular hydatid cysts from slaughtered animal: (A) fertile cyst, (B) sterile cyst, (C) calcified cyst.
It was observed that there was a statistical difference between the viability rate of protoscolex sheep liver and camel liver at $10 \mathrm{~min}$ $(P<0.05)$. It was also the case of the lung of sheep and camel at $10 \mathrm{~min}$ $(P<0.01)$. However, for the first $5 \mathrm{~min}$ no statistical difference was observed between the viability rate of protoscolex for sheep and camel $(P>0.05)$, as illustrated in Table 9. In addition, it was observed that there was no correlation relationship among the different organs of sheep and camel, but it was also observed that there was a correlation between the same organ of the same animal between 5 and $10 \mathrm{~min}$ : liver sheep $(\mathrm{r}=0.845)$; lung sheep $(\mathrm{r}=0.818)$; liver camel $(\mathrm{r}=0.758)$, and lung camel $(\mathrm{r}=0.435)$ illustrated in Table 10 .

\section{Discussion}

\section{Prevalence of variation of hydatid cysts in slaughtered} livestock

Cystic hydatid disease is one of the most widespread and serious helminthic zoonotic infections in the world. Usually, livestock species are more susceptible to infection by contamination through the viable eggs of E. granulosus [13]. In most studies conducted on the prevalence of cystic hydatid disease in livestock, the main source of data is obtained from abattoirs. However, in many countries, it is only in the government run abattoirs in the urban centers that have veterinarians who supervise the slaughter. In contrast, most of the abattoirs that are not run by the government do not have veterinarians to supervise the slaughter. Also, none of the abattoirs, especially in the rural areas of the Middle Eastern countries have veterinarians to supervise the slaughter. Furthermore, in such areas, it is common to slaughter livestock in the backyards, especially during religious festivals like Aid Eladha.

The rate of infection in camels $(12.5 \%)$ was higher than that in sheep and cattle (10.5\%, 10.6\% respectively). This finding concurred with that of Haridy et al. [14] from Egypt, where they reported camels play the important role in the local sustenance of the life cycle. However, the infection in camels from Tunisia according to Lahmar et al. [15] and Azlaf and Dakkak [16], in Morocco was similar to that of the present study, thus implying that camels are the main host for transmission of the hydatid infection in North Africa. Moreover, the infection rate in sheep from Morocco by Azlaf and Dakkak [16] was similar to that of the present study, but the infection in cattle $(22.98 \%)$ was higher in Morocco than of the present study (10.56\%). Lahmar et al. [17] found the infection rate in sheep from Tunisia (10.41\%) was similar to the rate in the present study. In Algeria, Bardonnet et al. [18] showed the infection rate in camels and cattle $(24.8 \%, 13.9 \%$, respectively) were higher than that in the present findings, meaning that the hydatid infection rates between countries in North Africa were similar. Between them, and indicating that similar factors effect on the transmission of this disease between the farm animals for the different countries.

Only some abattoirs from the present study had veterinarians to supervise the slaughters. However, when the residents needed camel meat for wedding celebrations, the camels were not slaughtered in the abattoir under the supervision of a veterinarian. It was only in the few abattoirs that different livestock were slaughtered under the supervision of a veterinarian.

One possible reason for the variation in the infection rate for all 
ISSN: 2325-4645

Table 7: Fertility rate of hydatid cysts of all slaughtered livestock.

\begin{tabular}{|c|c|c|c|}
\hline & Sheep & Camel & Cattle \\
\hline Fertile cysts & $208(80.0 \%)$ & $84(84.0 \%)$ & $0(0.0 \%)$ \\
\hline Sterile cysts & $40(15.4 \%)$ & $9(9.0 \%)$ & $7(58.3 \%)$ \\
\hline Calcified cysts & $12(4.6 \%)$ & $7(7.0 \%)$ & $5(41.6 \%)$ \\
\hline
\end{tabular}

Table 8: Fertility rate of hydatid cysts of different slaughtered livestock based on organ.

\begin{tabular}{|c|c|c|c|c|c|c|c|c|c|}
\hline & \multicolumn{3}{|c|}{ Fertile cysts } & \multicolumn{3}{|c|}{ Sterile cysts } & \multicolumn{3}{|c|}{ Calcified cysts } \\
\hline & Camel & Sheep & Cattle & Camel & Sheep & Cattle & Camel & Sheep & Cattle \\
\hline Liver cysts & $\begin{array}{c}23 \\
(27.4 \%)\end{array}$ & $112(53.6 \%)$ & $\begin{array}{c}0 \\
(0.0 \%)\end{array}$ & $\begin{array}{c}3 \\
(33.0 \%)\end{array}$ & $\begin{array}{c}17 \\
(43.0 \%)\end{array}$ & $\begin{array}{c}3 \\
(43.0 \%)\end{array}$ & $\begin{array}{c}2 \\
(29.0 \%)\end{array}$ & $\begin{array}{c}6 \\
(50.0 \%)\end{array}$ & $\begin{array}{c}3 \\
(60.0 \%)\end{array}$ \\
\hline Lung cysts & $\begin{array}{c}56 \\
(66.7 \%)\end{array}$ & $\begin{array}{c}82 \\
(39.4 \%)\end{array}$ & $\begin{array}{c}0 \\
(0.0 \%)\end{array}$ & $\begin{array}{c}4 \\
(44.0 \%)\end{array}$ & $\begin{array}{c}19 \\
(47.0 \%)\end{array}$ & $\begin{array}{c}4 \\
(57.0 \%)\end{array}$ & $\begin{array}{c}4 \\
(57.0 \%)\end{array}$ & $\begin{array}{c}4 \\
(33.0 \%)\end{array}$ & $\begin{array}{c}2 \\
(40.0 \%)\end{array}$ \\
\hline Mesentery cysts & $\begin{array}{c}0 \\
(0.0 \%)\end{array}$ & $\begin{array}{c}5 \\
(2.4 \%)\end{array}$ & $\begin{array}{c}0 \\
(0.0 \%)\end{array}$ & $\begin{array}{c}0 \\
(0.0 \%)\end{array}$ & $\begin{array}{c}3 \\
(7.5 \%)\end{array}$ & $\begin{array}{c}0 \\
(0.0 \%)\end{array}$ & $\begin{array}{c}0 \\
(0.0 \%)\end{array}$ & $\begin{array}{c}2 \\
(17.0 \%)\end{array}$ & $\begin{array}{c}0 \\
(0.0 \%)\end{array}$ \\
\hline Spleen cysts & $\begin{array}{c}5 \\
(5.9 \%)\end{array}$ & $\begin{array}{c}3 \\
(1.44 \%)\end{array}$ & $\begin{array}{c}0 \\
(0.0 \%)\end{array}$ & $\begin{array}{c}2 \\
(22.0 \%)\end{array}$ & $\begin{array}{c}1 \\
(2.5 \%)\end{array}$ & $\begin{array}{c}0 \\
(0.0 \%)\end{array}$ & $\begin{array}{c}1 \\
(14.0 \%)\end{array}$ & $\begin{array}{c}0 \\
(0.0 \%)\end{array}$ & $\begin{array}{c}0 \\
(0.0 \%)\end{array}$ \\
\hline
\end{tabular}

Table 9: Statistical variation of fertile cysts in slaughtered sheep and camel based on organ.

\begin{tabular}{|c|c|c|c|c|c|c|c|c|c|}
\hline & \multicolumn{5}{|c|}{ Sheep } & \multicolumn{4}{|c|}{ Camel } \\
\hline & Liver & Lung & Mesentery & Spleen & & Liver & Lung & Spleen & \\
\hline Mean \pm S.E & $56 \pm 5$ & $41 \pm 6$ & $5.5 \pm 0.5$ & $1.5 \pm 1.2$ & & $11.5 \pm 2.5$ & $28 \pm 2$ & $2.5 \pm 0.5$ & \\
\hline Sig & $\begin{array}{l}N S< \\
\leftarrow \\
\leftarrow\end{array}$ & & $\leftarrow$ & & & $\leftarrow$ & $\begin{aligned} & N S \\
> & \end{aligned}$ & $\rightarrow$ & NS \\
\hline
\end{tabular}

NS = non-significant difference $\quad$ * significant difference $P<0.05$.

Table 10: Viability rate of protoscolex of hydatid cysts in slaughtered sheep and camels.

\begin{tabular}{|c|c|c|c|c|c|c|c|c|}
\hline & \multicolumn{4}{|c|}{ Sheep } & \multicolumn{4}{|c|}{ Camel } \\
\hline & \multicolumn{2}{|c|}{ Liver } & \multicolumn{2}{|c|}{ Lung } & \multicolumn{2}{|c|}{ Liver } & \multicolumn{2}{|c|}{ Lung } \\
\hline & $5 \min$ & $10 \min$ & $5 \min$ & $10 \mathrm{~min}$ & $5 \mathrm{~min}$ & $10 \mathrm{~min}$ & $5 \min$ & $10 \mathrm{~min}$ \\
\hline Mean \pm S.E & $22.96 \pm 1.1$ & $15.2 \pm 1.4$ & $22.7 \pm 0.61$ & $13.8 \pm 1.2$ & $21.2 \pm 0.52$ & $18.3 \pm 0.4$ & $23.9 \pm 0.57$ & $18.3 \pm 0.65$ \\
\hline Sig & & & \multicolumn{2}{|c|}{ ** } & \multicolumn{2}{|c|}{ * } & & ** \\
\hline
\end{tabular}

* Significant difference $\mathrm{P}<0.05 . \quad$ ** High significant difference $\mathrm{P}<0.01$.

the slaughtered livestock in overall study areas could be the variations in environmental factors, such as temperature, humidity and the nature of the pasture. Furthermore, these variations could be related to the different strains of E. granulosus [19].

For the findings of the present research, there were some significant differences in infection rates in some seasons, but not for others. This was shown in slaughtered camels, where differences were only seen between spring and autumn and between winter and summer. Similarly, Ibrahim [20] found significant differences in infection rates between spring and autumn in Saudi Arabia while Daryani et al. (2007) [12] found significant differences in infection rates between autumn and winter in Iran.

\section{Infection rate of hydatid cysts in livestock based on the} organ

The findings of this current study indicated that the rate of infection differed non significantly according to the sex of the slaughtered livestock. For instance, in the case of slaughtered sheep, males were more likely to have a hydatid cyst infections than females while the highest rate of infection in slaughtered female camel and cattle compared to males because the people there preferred to slaughter females, especially the oldest females than males. The findings of this present study are reflected in the findings of Ibrahim [20] (2009) for Saudi Arabia, Tashani et al. (2002) [10] in Libya and Al Yaman et al. (1985) [21] in Jordan.

These differences could be due to a number of reasons. For instance, the inhabitants preferred to slaughter young male sheep rather than juvenile females, while the older animals were more likely to be infected with hydatid cysts than the younger animals (Ibrahim, 2009) [20].

In the present study, the livers of sheep and cattle were found 
to be more commonly infected with hydatid cysts than the lungs and other organs. These findings were supported by other studies conducted in Libya for sheep and cattle by Khan et al. (2001) [22], Gusbi et al. (1987, 1990) [7,8], Al-Khalidi (1998) [23] and Tashani et al. (2002) [10]. The reason why the liver in sheep and cattle is most commonly infected is because the bile duct in the liver receives the blood with the oncospheres after the blood has passed the duodenum (Soulsby, 1982)[24].

In the case of camels, the lung was the organ most frequently infected by hydatid cysts, as similarly reported by other workers (Tashani et al. [10]; Elmajdoub et al. [11]; Al-Khalidi [23], Ibrahim and Gusbi [25]; Ibrahim and Craig [9]; Buishi [26]; Abdel-Hafez and Al Yaman [27] and Kamhawi et al [28]). Unlike sheep and cattle, camels do not have bile ducts, thus the oncosphere passes through the blood and flows to the lungs and stays there. In addition the tissue of camel liver is tough and solid, making it difficult for the oncosphere to grow normally, whereas, the lung tissue is smoother and softer, making it easier for the oncosphere to grow faster.

\section{Fertility and viability of cystic echinococcosis}

Data on the fertility and viability of hydatid cysts in various livestock animals play an important role in providing credible indicators of the importance of each livestock as a possible source of infection of final hosts, especially dogs. Usually, depending on the host, the size and location of cysts, hydatid cysts have different rates of fertility. In this regard, a number of studies have been conducted in Libya to estimate the fertility and viability rates of protoscoleces in a variety of slaughtered animals: Tashani et al. [10], Elmajdoub et al. [11], Khan et al. [22], Buishi [26]. In addition, studies had also been conducted in other countries, for example, Scala et al. [29] in Italy, Ahmed et al. [30] in Pakistan and Daryani et al. [31] from Iran.

In the present study, it was observed that the cysts in camels were more fertile than those of sheep, but all examined cysts from cattle were sterile. The fertility rates of cysts from sheep some areas were higher than those from other areas, because the sheep strains in those areas were more abundant than other regions, whereas, one area may have different strains of E. granulosus. Thus, infection may occur as a result of mixtures of strains.

In terms of hepatic cysts, the fertility rate was higher in slaughtered sheep than camels. The reverse was noticed in pulmonary cysts, where the fertility rate was higher in camels than in sheep because the lung of the camel is a more suitable organ for fertile cyst, as it is known to have a more conducive habitat for the growth of the metacestode [32]. The findings from the present study are supported by those of Elmajdoub et al. and Tashani et al. [10,11] from Libya and Daryani et al. [31] from Iran. Furthermore, Dalimi et al. [33] from Iran observed that the hepatic cysts of sheep were more fertile than pulmonary cysts, while Kamhawi et al. [28] from Jordan found hepatic cysts from sheep were more fertile than those from the camel.

Sterile hydatid cysts were noticed as early as 1928 by Dew [34]. He stated that the sterility or the acephalocyst might be due to the inherent inability to reproduce, but in the majority of cases it is due to some abnormal local conditions. He added that the availability of nourishment is probably the most important factor and is influenced by the location of the parasite and the condition of the adventitious coat. Sterile hydatid cysts may also be due to infection by unspecific strain.

The findings of the present study indicated that all cysts from cattle were sterile $(58.3 \%)$ and calcified (41.6\%). These findings were similar to those of Elmajdoub et al. [11] and Khan et al. [22] from Libya. However, Tashani et al. [10] found a few fertile cysts in slaughtered cattle in eastern Libya. Gusbi et al. (1990) [8] argued that the cysts from cattle never appeared to be fertile; thus it seemed impossible that cattle could play any major role in the transmission of E. granulosus. This would indicate that cattle are an unsuitable source of transmission of E. granulosus in Libya.

In their study, Kebede et al. [35] from Ethiopia recorded that the fertility rate increased with the age of the cyst, but the age of the animal had no effect on the fertile cyst. Such an observation is similar to the findings of the present study which demonstrated that the fertility rates of sheep and camel slaughtered at several ages were comparable. The rate of viable protoscoleces from fertile cysts from sheep and camel slaughtered were comparable within the first five minutes, but after $10 \mathrm{~min}$, the findings from this present study demonstrated that the protoscoleces from camels were still viable compared to those from sheep. In a study conducted in Saudi Arabia, Ibrahim (2009) found the viable protoscoleces from sheep were higher than that of camels, an observation similarly noted by Dalimi et al. [33]. However, the findings from the present study showed the viable of protoscoleces in camels (60.93\%) were higher than those in sheep (48.4\%) after $10 \mathrm{~min}$

The differences in the findings may be due to the fact that in the process of determining the viability rate using $1 \%$ eosin stain, it might be necessary to estimate the time taken by the protoscoleces to absorb the stain, because the viable protoscoleces did not absorb the stain until dead, but if the protoscolex is dead or not viable, the stain would enter into the protoscolex after 5-10 min. The data in the present study recorded high, significant differences between the viable protoscoleces from liver and lung hydatid cysts in both sheep and camels. Usually, the variation in the viability of protoscoleces might be related to the difference in the immunological response of each host. It might also be related to the calcareous corpuscles in the protoscoleces, of which a large number were non-viable. In summary, it could be argued that the fertility rate of the cysts determines the actual role of a particular species of livestock in the cycle of hydatid infection.

\section{References}

1. Yang YR, Rosenzvit MC, Zhang LH, Zhang JZ, McManus DP (2005) Molecular study of Echinococcus in west-central China. Parasitology 131 547-555.

2. Eckert J, Schantz PM, RB Gasser, PR Torgerson, AS Bessonov, SO Movsessia, A Thakur, F Grimm, and MA Nikogossian (2001) Geographic distribution and prevalence In: Eckert J, Gemel MA, Meslin FX and Pawlowski ZS (Ed), WHO/OIE Mamual on Echinococcosis in Humans and animals: A public health problem of Global Concern, World Organisation for animal Health, Paris, France, 100-143.

3. Battelli G, Mantovani A, Seimenis A (2002) Cystic echinococcosis and the Mediterranean Region: A long-lasting association. Parassitologia 44: 43-57.

4. Dakkak A (2010) Echinococcosis/ hydatidosis: A serve threat in Mediterranean countries. Vet Parasitol 174: 2-11.

5. Lahmar S, Kilani M, Torgerson PR, Gemmell MA (1999) Echinococcus 
granulosus larvae in the livers of sheep in Tunisia: The effects of host age. Ann Trop Med Parasitol 93: 75-81.

6. Dar FK and Taguri SC (1979) Epidemiology and epizootiology hydatidosis in Libya, and recommendations for programmer of surveillance and control of the disease, Garyonis Medical Journal 2:11-15

7. Gusbi AM, Awan MA, Beesley WN (1987) Echinococcis in Libya. II Prevalence of hydatidosis (Echinococcus granulosus) in sheep. Ann Trop Med Parasitol 81: 35-41.

8. Gusbi AM, Awan MA, Beesley WN (1990) Echinococcosis in Libya. IV. Prevalence of hydatidosis (Echinococcus granulosus) in goats, cattle and camels. Ann Trop Med Parasitol 84: 477-482.

9. Ibrahem MM, Craig PS (1998) Prevalence of cystic echinococcosis in camels (Camelus dromedarius) in Libya. J Helminthol 72: 27-31.

10. Tashani OA, Zhang LH, Boufana B, Jegi A, McManus DP (2002) Epidemiology and strain characteristics of Echinococcus granulosus in the Benghazi area of eastern Libya. Ann Trop Med Parasitol 96: 369-381.

11. Elmajdoub LO, K Elhoti and N Haded(2007) Prevalence of Hydatid Disease in Slaughtered Livestock Animals from Misurata Abattoirs, (Libya). Journal of Union of Arab Biologists Cairo 28A: 163-174

12. Daryani A, Alaei R, Arab R, Sharif M, Dehghan MH (2007) The prevalence, intensity and viability of hydatid cysts in slaughtered animals in the Ardabil province of Northwest Iran. J Helminthol 81: 13-17.

13. Schantz PM (1997) Sources and uses of surveillance data for cystic echinococcosis. In: Compendium on cystic echinococcosis in Africa and Middle Eastern countries with reference to Morocco, eds. Andersen FL, Ouhell $\mathrm{H}$ and Kachani M. Brigham Young University, USA, 72-84.

14. Haridy FM, Ibrahim BB, Morsy TA ( 2000) Sheep-dog-man. The risk zoonotic cycle in hydatidosis. J Egypt Soc Parasitol 30: 423-429.

15. Lahmar S, Debbek H, Zhang LH, McManus DP, Souissi A (2004) Transmission dynamics of the Echinococcus granulosus sheep-dog strain (G1 genotype) in camels in Tunisia. Vet Parasitol 121: 151-156.

16. Azlaf R, Dakkak A (2006) Epidemiological study of the cystic echinococcosis in Morocco. Vet Parasitol137: 83-93.

17. Lahmar S, Chéhida FB, Pétavy AF, Hammou A, Lahmar J (2007) Ultrasonographic screening for cystic echinococcosis in sheep in Tunisia. Vet Parasitol 143: 42-49.

18. Bardonnet K, Benchikh-Elfegoun MC, Bart JM, Harraga S, Hannache N (2003) Cystic echinococcosis in Algeria: Cattle act as reservoirs of a sheep strain and may contribute to human contamination. Veterinary Parasitology 116: 35-44.

19. McManus DP (2006) Molecular discrimination of taeniid cestodes. Parasitol Int 55: 31-37.

20. Ibrahim MM (2009) Study of cystic echinococcosis in slaughtered animals in Al Baha region, Saudi Arabia: Interaction between some biotic and abiotic factors. Acta Trop 113: 26-33.
21. Al-Yaman FM, Assaf L, Hailat N, Abdel-Hafez SK (1985) Prevalence of hydatidosis in slaughtered animals from North Jordan. Ann Trop Med Parasitol 79: 501-506.

22. Khan AH, El-Buni AA, Ali MY (2001) Fertility of the cysts of Echinococcus granulosus in domestic herbivores from Benghazi, Libya, and the reactivity of antigens produced from them. Ann Trop Med Parasitol 95: 337-342.

23. Al-Khalidi NW (1998) Cystic echinococcosis in sheep, goats, cattle and camels in Shahat abattoir, Al- Jabal, Libya. Proceedings of the Third Annual Meeting for Animal Production Under Arid Conditions, 1:143-149.

24. Soulsby EJL (1982) Helminths, Arthropods and Protozoa of domesticated animals. 119-122, Edition-7. Bailliere, Tindall, London.

25. Ibrahim MM and AM Gusbi (1997) Cystic echinococcosis in North Africa (Excluding Morocco): veterinary aspects. In: Compendium on cystic echinococcosis in Africa and Middle Eastern countries with reference to Morocco, eds. Andersen $\mathrm{FL}$, Ouhell $\mathrm{H}$ and Kachani M Brigham Young University, USA, 207- 222.

26. Buishi IE (2004) Epidemiology of canine echinococcosis in northwest Libya, northwest Kenya and mid-Wales UK: Ph.D. Thesis in Parasitology, Bioscience Research Institute, School of Environment and life Science University of Salford.

27. Abdel-Hafez SK and Al-Yaman FM (1989) Spleen hydatidosis in sheep from North Jordan. Vet Parasitol 30: 191-196.

28. Kamhawi S, Hijjawi N, Abu-Gazaleh A, Abbass M (1995) Prevalence of hydatid cysts in livestock from five regions of Jordan. Ann Trop Med Parasitol 89: 621-629.

29. Scala A, Garippa G, Varcasia A, Tranquillo VM, Genchi C (2006) Cystic echinococcosis in slaughtered sheep in Sardinia (Italy). Vet Parasitol 135: 33-38.

30. Ahmed S, Nawaz M, Gul R, Zakir M and Razzaq A (2006) Some epidemiological aspects of hydatidosis of lungs and livers of sheep and goats in Quetta, Pakistan. Pakistan J Zool 38: 1-6.

31. Daryani A, Sharif M, Amouei A, Nasrolahei M. (2009) Fertility and viability rates of hydatid cysts in slaughtered animals in the Mazandaran Province, Northern Iran. Trop Anim Health Prod 41: 1701-1705.

32. Rausch RL (1997) Echinococcus granulosus: Biology and ecology in compendium on cystic echinococcosis in Africa and Middle Eastern countries with reference to Morocco, by Andersen FL, Ouhell $\mathrm{H}$ and Kachani M. ed, Brigham Young University, USA,18-53.

33. Dalimi A, Motamedi G, Hosseini M, Mohammadian B, Malaki H (2002) Echinococcosis/hydatidosis in western Iran. Vet Parasitol105: 161-171.

34. Dew HR (1928) Hydatid disease its pathology, diagnosis and treatment. Sydeney. The Australian Medical Publishing Company Limited.

35. Kebede N, Mekonnen H, Wossene A, Tilahun G (2009) Hydatidosis of slaughtered cattle in Wolaita Sodo Abattoir, southern Ethiopia. Trop Anim Health Prod 41: 629-633. 